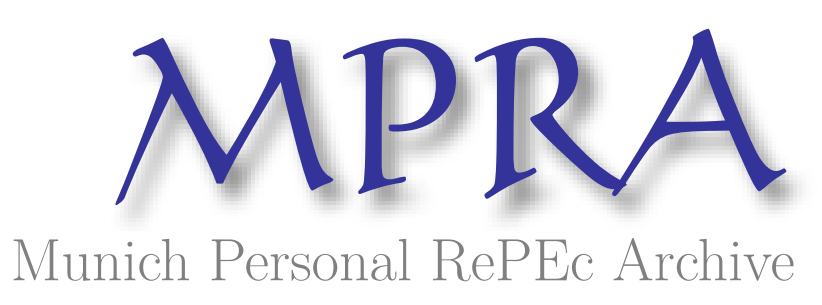

\title{
Long memory and non-linearity in Stock Markets
}

Bond, Derek and Dyson, Kenneth

September 2006

Online at https://mpra.ub.uni-muenchen.de/252/

MPRA Paper No. 252, posted 09 Oct 2006 UTC 


\title{
Long memory and non-linearity in Stock Markets
}

\author{
Derek Bond* and Kenneth A. Dyson \\ School of Business, Retail and Financial Services, \\ University of Ulster at Coleraine, \\ BT52 1SA, United Kingdom \\ *corresponding author: d.bond@ulster.ac.uk
}

September 20, 2006

\begin{abstract}
In this paper the long memory and non-linear properties of share prices in the UK's Stock Exchange and AIM are explored. The results suggest that the most commonly traded shares exhibit long memory thus raising interesting issues about the validity of normal assumptions of market efficiencies.
\end{abstract}




\section{Introduction}

Gil-Alana (2006) highlights the issue of whether the time series behaviour of stock market indexes can be described by a fractional representation. Such a possibility could be due to long memory or nonlinearities and has serious consequences for the efficient market hypothesis in stock markets. In this paper the issues are examined further using the time-series of individual share prices for one hundred companies from the London Main(FTSE) and Alternative Investment(AIM) markets. A simple fractional augmented Dickey-Fuller $(F A D F)$ test is used to test for long memory utilising a range of consistent estimates of the fractional differencing parameter $d$. The possibility of non-linearity is investigated by applying both random field based tests and traditional tests for structural breaks.

\section{Background}

Weak form market efficiency posits that the current share price fully reflects the information implicit in the share price history of a company. This implies that the share price time series, say $\left\{P_{i t}\right\}_{t=0}^{T}$ for share $i$, does not exhibit serial correlation, or 'memory'. Recent literature puts forward the case for a generic random walk type model, albeit one with less stringent assumptions than those imposed in earlier literature on market efficiency. Traditionally the analysis has been whether $\left\{P_{i t}\right\}_{t=0}^{T}$ is $I(1)$ or $I(0)$. In the $I(0)$ case $P_{i t}$ is covariance stationary and displays the property of short-memory. In the $I(1)$ case $P_{i t}$ is non-stationary and non-mean reverting. Fractional integration relaxes the assumption that the differencing parameter $d$ is integer. A time-series process with $0<d<1$ is defined as a long-memory process. If $0<d<0.5$ the series $P_{i t}$ is covariance stationary, but the autocorrelation function is more persistent, with a longer decay period, than when $d=0$. If $0.5 \leq d<1 P_{i t}$ is not covariance stationary, but is still mean reverting, with a persistent, slowly decaying autocorrelation function. Thus, if $P_{i t}$ is $I(d)$ with $0<d<1$ it exhibits memory 
and is thus not consistent with weak-form efficiency.

While studies focusing on the non-stationarity of time series have dominated the literature, increasingly attention is focusing on the issue of whether series that appear integrated of order $>0$ are actually non-linear but stationary series. Diebold \& Inoue (2001) showed that long memory and structural change are closely related in the $I(d)$ case, but warned:

$\therefore$ that the temptation to jump to the conclusion of "structural change producing spurious inferences of long memory" should be resisted.'

(Diebold \& Inoue 2001, p.157)

\section{Methodology}

To test whether share prices exhibit long memory and/or non-linearity, a variety of techniques are applied to the time-series of the top 25 and bottom 25 (by market capitalisation) companies in both the FTSE and the AIM from the $1^{\text {st }}$ January 1998 to $31^{\text {st }}$ December 2004, inclusive. The selection allows for the investigation of two hypotheses. The first is that there are differences in how information is processed between listed markets. The expectation being that AIM listed companies will be subject to less scrutiny by market participants than their FTSE counterparts and more prone to information inefficiencies. Therefore their share prices are more likely to exhibit long memory. The second hypothesis is the relative size hypothesis. Larger companies should be subject to greater scrutiny by market participants and therefore be less prone to information inefficiencies. The tendency towards long memory should thus be more prominent in smaller companies.

Firstly, long memory is investigated using Dolado, Gonzalo \& Mayoral (2002) $F A D F$ test and consists of estimating the equation:

$$
\Delta P_{t}=\theta \Delta^{d} P_{t-1}+\sum_{i=1}^{p} \varsigma_{i} \Delta P_{t-i}+\epsilon_{t}
$$


The test of $H_{0}: \theta=0$ is a test of the hypothesis that $d=1$. Using various consistent estimates of $d$ (Shimotsu (2006) exact Whiittle estimators ${ }^{1}$, semiparametric estimator of Geweke \& Porter-Hudak (1983) and two parametric estimators, the exact maximum likelihood and nonlinear least squares, available in the ARFIMA package of Oxmetrics (Doornik \& Ooms 1999) the test statistic is asymptotically normal under $H_{0}$.

To investigate the possibility of non-linearity in the series both traditional parametric tests for structural breaks and random field based inference are used. In both cases the possibility of the share prices following a non-linear $\operatorname{AR}(1)$ process or some form of transition models was investigated. Using the suite of tests proposed by Bai \& Perron (2003) the models

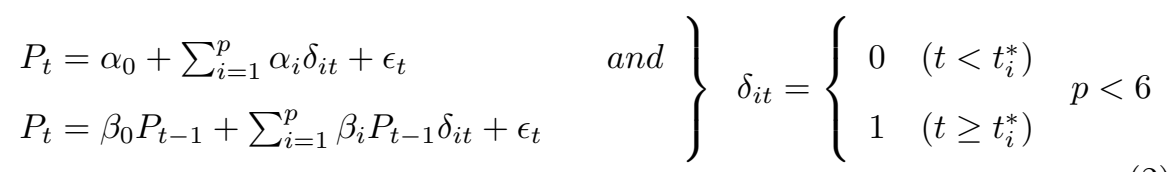

were investigated. ${ }^{2}$ The random field tests for non-linearity are based on two special cases of the model introduced in Hamilton (2001).

$$
\begin{array}{ll}
P_{t} & =\alpha+\beta P_{t-1}+\lambda m(g \odot \mathbf{P})+\epsilon_{\mathbf{t}} \quad \text { and } \\
P_{t} & =\alpha+\beta P_{t-1}+\psi t+\lambda m(g \odot \mathbf{x})+\epsilon_{\mathbf{t}}
\end{array}
$$

where $x_{t}=\left(P_{t}, t\right)$, and $\odot$ denotes element by element multiplication. In (3) $m($.$) are random fields and g$ is a $(k \times 1)$ vector $k=1$ or 2 . The parameter $g$ can be seen as a measure of the impact of either $P$ or $t$ on the non-linearity. The scalar parameter $\lambda$ as a measure of the degree of non-linearity. A simple test for non-linearity is to test $H_{0}: \lambda=0$. Hamilton's approach was to assume a gaussian random field, meaning that the field is defined by its first two moments, and deriving a simple $\chi^{2}$ test of the null hypothesis derived from a generalised linear regression model interpretation. In Dahl \& Gonzalez-Rivera (2003) the basic test was extended by the introduction of three tests that took account, to various degrees, the problems of nuisance parameters. It was shown in Dahl 
\& Gonzalez-Rivera (2003) that the four test were generally more powerful than other tests of non-linearity and fairly insensitive to model misspecification. ${ }^{3}$

\section{Results}

Tables 1 and 2 summarise the principal findings of the study. A series is classified as either fractional or $I(1)$ when over $85 \%$ of the $F A D F$ tests indicate this otherwise the series has been classified as indeterminate. In all fractional cases $d$ was non-stationary.

For the FTSE $64 \%$ of the largest companies exhibit strong signs of fractionality whilst none of the smallest companies do. Conversely, $32 \%$ of the largest companies and $92 \%$ of the smallest companies exhibit signs of weak form efficiency. The remaining $4 \%$ and $8 \%$ being indeterminate. These result seem contrary to the relative size hypothesis. The results of the non-linearity tests are generally inconclusive. The one exception is the single large company where the $F A D F$ was inconclusive - here there is a strong indication of some form of non-linearity. Similar, less strong, results follow for the 2 small companies where the $F A D F$ is inconclusive. Amongst the smaller companies there is more evidence that in some cases the non-stationarity could be due to non-linearity.

For the AIM the results are significantly different, $8 \%$ of the largest companies and $24 \%$ of the smallest companies exhibit signs of fractionality. The majority of large companies, $76 \%$, are weak form efficient whilst only $44 \%$ of the smallest companies are. There are many more companies, $16 \%$ and $32 \%$ of the largest amd smallest respectively, being indeterminate. These result support the relative size hypothesis but when compared with the FTSE are contrary to the relative markets efficiency hypothesis. Again the results of the non-linearity tests are generally inconclusive. The increased probability of non-linearity amongst smaller companies together with the larger number of inconclusive fractionality results might be explained by thin trading. 


\section{Discussion and Conclusion}

In this paper the work of Gil-Alana (2006) has been extended by investigating the time-series characteristics of individual share price series using a simple $F A D F$ test and a suite on non-linearity tests. Data from the top and bottom 25 firms in the FTSE 100 index and the AIM were investigated. The results of the study appear to cast doubt on whether the larger companies in the FTSE are weak form efficient. Thus someone using some form of trading rule with these companies, operating in 'real-time', may be capable of profiting from these inefficiencies. This is an interesting finding, as theory posits that stock price markets are information efficient. The concept of market efficiency is built upon the foundation that markets are at least weak form efficient. If this does not hold, then neither do the stricter definitions. If anything, the results provide evidence that information efficiency is more prevalent the smaller the company, and given the caveat re thin trading, the smaller the market.

The possibility of inefficiencies in the FTSE needs to be investigated further. For example, a possible explanation for the inefficiency in the FTSE may be the use from the late 1980's onwards of automated trading systems. Such systems may create self-perpetuating patterns, thereby creating long-memory, from which traders may profit.

Given the inconclusive nature of the Hamilton-Dahl and Bai-Perron tests the issue of whether the non-stationarity in share prices is in part due to nonlinearity needs to be investigated further. This could be by trying to model the possible non-linearity through random field or STR models. Or it could be by examining the behaviour of the consistent semi-parametric estimators of $d$ in line with Diebold \& Inoue (2001). 


\section{References}

Bai, J. \& P. Perron (2003), 'Computation and analysis of multiple structural change model', Journal of Applied Econometrics 18, 1-22.

Dahl, C. M. \& G. Gonzalez-Rivera (2003), 'Testing for neglected nonlinearity in regression models based on the theory of random fields', Journal of Econometrics 114, 141-164.

Diebold, F. X. \& A. Inoue (2001), 'Long memory and regime switching', Journal of Econometrics 105, 131-159.

Dolado, J. J., J. Gonzalo \& L. Mayoral (2002), 'A fractional dickey-fuller test for unit roots', Econometrica 70, 1963-2006.

Doornik, J.A. \& M Ooms (1999), 'A package for estimating,forecasting and simulating arfima models: Arfima package 1.0 for ox'. Discussion Paper, Nuffield College, Oxford.

Geweke, J. \& S. Porter-Hudak (1983), 'The estimation ansd application of longmemory time series models', Journal of Time Series Analysis 4, 221-237.

Gil-Alana, L.A. (2006), 'Fractional integration in daily stock market indexes', Review of Financial Economics 15, 28-48.

Hamilton, J. D. (2001), 'A parametric approach to flexible nonlinear inference', Econometrica 69, 537-573.

Shimotsu, K. (2006), Exact local whittle estimation of fractional integration with unknown mean and time trend, Working Papers 1061, Queen's University, Department of Economics. 
Table 1: Stationarity Results

\begin{tabular}{|c|c|c|c|c|c|c|}
\hline \multirow[t]{2}{*}{ Market } & \multicolumn{3}{|c|}{25 Largest Companies } & \multicolumn{3}{|c|}{25 Smallest Companies } \\
\hline & Fractional & $I(1)$ & Indeterminate & Fractional & $I(1)$ & Indeterminate \\
\hline FTSE & & & & & & \\
\hline$\underset{\text { Percent }}{\text { Number }}$ & $\begin{array}{c}16 \\
64 \%\end{array}$ & $\begin{array}{c}8 \\
32 \%\end{array}$ & $\begin{array}{c}1 \\
4 \%\end{array}$ & $\begin{array}{c}0 \\
0 \%\end{array}$ & $\begin{array}{c}23 \\
92 \%\end{array}$ & $\begin{array}{c}2 \\
8 \%\end{array}$ \\
\hline AIM & & & & & & \\
\hline Number & $\begin{array}{c}2 \\
8 \%\end{array}$ & $\begin{array}{c}19 \\
76 \%\end{array}$ & $\begin{array}{c}4 \\
16 \%\end{array}$ & $\begin{array}{c}6 \\
24 \%\end{array}$ & $\begin{array}{c}11 \\
44 \%\end{array}$ & $\begin{array}{c}8 \\
32 \%\end{array}$ \\
\hline
\end{tabular}

Table 2: Percentage of linearity tests significant at 5\% levels

\begin{tabular}{|c|c|c|c|c|c|}
\hline & & \multirow{2}{*}{\multicolumn{2}{|c|}{$\begin{array}{c}\text { Hamilton-Dahl } \\
\text { model }\end{array}$}} & \multirow{2}{*}{\multicolumn{2}{|c|}{$\begin{array}{c}\text { Bai-Perron } \\
\text { model }\end{array}$}} \\
\hline & & & & & \\
\hline & & $P_{t-1}$ & $P_{t-1}, t$ & $\beta$ & $\alpha$ \\
\hline \multirow[t]{4}{*}{ FTSE Largest } & & $\%$ & $\%$ & $\%$ & $\%$ \\
\hline & Fractional & 11 & 13 & 6 & 38 \\
\hline & $\begin{array}{l}I(1) \\
(n=8)\end{array}$ & 31 & 38 & 0 & 63 \\
\hline & $\underset{(n=1)}{\text { Indeterminate }}$ & 75 & 75 & 0 & 100 \\
\hline \multicolumn{6}{|l|}{ FTSE Smallest } \\
\hline & $\underset{(n=0)}{\text { Fractional }}$ & . & . & . & . \\
\hline & $\begin{array}{c}I(1) \\
(n=23)\end{array}$ & 8 & 33 & 30 & 30 \\
\hline & $\underset{(n=2)}{\text { Indeterminate }}$ & 38 & 38 & 0 & 50 \\
\hline \multirow[t]{4}{*}{ AIM Largest } & & $\%$ & $\%$ & $\%$ & $\%$ \\
\hline & $\underset{(n=2)}{\text { Fractional }}$ & 50 & 50 & 0 & 50 \\
\hline & $\begin{array}{c}I(1) \\
(n=19)\end{array}$ & 8 & 14 & 16 & 11 \\
\hline & $\underset{(n=4)}{\text { Indeterminate }}$ & 0 & 0 & 0 & 25 \\
\hline AIM Smallest & Fractional & 16 & 46 & 0 & 50 \\
\hline & $\begin{array}{c}I(1) \\
(n=11)\end{array}$ & 7 & 25 & 27 & 45 \\
\hline & $\underset{(n=8)}{\text { Indeterminate }}$ & 50 & 32 & 25 & 63 \\
\hline
\end{tabular}

Note: Each variable has 4 tests applied for each method/model 


\section{Notes}

${ }^{1}$ using the MATLAB code supplied by the authors.

${ }^{2}$ the Gauss code provided by the authors was used.

${ }^{3}$ The Gauss code supplied by Hamilton (http://weber.ucsd.edu/ jhamilto) was used. 